\title{
The German Bight (North Sea) is a nursery area for both locally and externally produced sprat juveniles
}

\author{
Hannes Baumann ${ }^{\mathrm{a}, *}$, Arne M. Malzahn ${ }^{\mathrm{b}}$, Rudi Voss ${ }^{\mathrm{c}}$, Axel Temming ${ }^{\mathrm{d}}$ \\ a School of Marine and Atmospheric Sciences, Stony Brook University, Stony Brook, NY, 11794-5000, USA \\ ${ }^{\mathrm{b}}$ Alfred Wegener Institute for Polar and Marine Research, Biologische Anstalt Helgoland, Building A, Ostkaje 1118, 27498 Helgoland, Germany \\ c Department of Economics, Sustainable Fishery, University of Kiel, Wilhelm-Seelig Platz 1, 24118 Kiel, Germany \\ ${ }^{d}$ Institute of Hydrobiology and Fisheries Sciences, Olbersweg 24, 22767, Hamburg, Germany
}

\section{A R T I C L E I N F O}

\section{Article history:}

Received 20 October 2008

Received in revised form 29 December 2008

Accepted 8 January 2009

Available online 22 January 2009

\section{Keywords:}

Nursery Area

Otolith Microstructure Analysis

Egg Production

Larval Production

Helgoland Roads

Temperature-Growth Relationship

\begin{abstract}
A B S T R A C T
To better understand the role of the German Bight (GB) as a nursery area for juvenile North Sea sprat Sprattus sprattus we sought to determine whether the area may receive only locally or also externally produced offspring. We sampled juveniles during 3 trawl surveys in the GB in August, September, and October 2004 and applied otolith microstructure analysis in order to reconstruct their distributions of the day-of-firstincrement-formation (dif). These were contrasted with spatial and seasonal patterns of sprat egg abundance in the GB and its adjacent areas, observed during 6 monthly plankton surveys. It was found that the majority of juveniles originated mainly from April/May 2004, coinciding with high spawning activity west of the GB, whereas spawning and larval production inside the GB peaked notably later, in May/June. This indicated that a large proportion of juveniles was produced outside the GB and transported subsequently into it through passive and/or active migration. Shifts to later mean difs from one survey to the next and length distributions indicative of the simultaneous presence of multiple cohorts, supported the notion that the GB is a complex retention and nursery area for sprat offspring from different North Sea spawning grounds and times. Later born juveniles had significantly faster initial growth rates than earlier born conspecifics, which was likely temperature-mediated, given the strong correlation between back-calculated growth histories and sea surface temperature as a proxy for thermal histories of juveniles $\left(r^{2}=0.52\right)$.
\end{abstract}

(c) 2009 Elsevier B.V. All rights reserved.

\section{Introduction}

Coastal regions often act as nursery areas for the larval and juvenile stages of marine fish. Such areas typically (i) show an enhanced primary and secondary production promoting cohort growth and hence survival (Anderson, 1988), (ii) receive offspring from other spawning areas due to passive larval transport, and (iii) have hydrographical features that favour offspring retention. Exploring the structure, function, and importance of nursery areas is in many ways highly relevant; for our general comprehension of ecosystems (including their potential need of protection from human exploitation, e.g., fishing), or specifically for understanding the dynamics of a particular fish population. The latter is because in most fish species juvenile survival variability (generated in nursery areas) significantly contributes to recruitment variability (Bradford, 1992; Leggett and Deblois, 1994; Baumann et al., 2006a), which in turn is the dominant source of fluctuations in fish abundance (Sissenwine, 1984; Heath, 1992).

The German Bight (GB) in the south-eastern North Sea has long been recognized as a nursery area for juveniles of many commercially

\footnotetext{
* Corresponding author. Tel.: +1 6316323137.

E-mail address: hannes.baumann@stonybrook.edu (H. Baumann).
}

important fish species, which are most abundant there between spring and fall (e.g., Clupeidae (Alshut, 1989), Gadidae (Berghahn, 1996), Pleuronectidae (Berghahn and Purps, 1998). The GB is known for its high levels of primary and secondary production (Tillmann et al., 2000) resulting from nutrient enrichment due to coastal upwelling, tidal mixing, and river outflow (Krause et al., 1986). The counterclockwise residual circulation in the southern North Sea (Otto et al., 1990, Fig. 1) provides a plausible mechanism for pelagic offspring transport towards the GB, while the Bights retentive circulation likely helps aggregating them in the area (Bartsch and Knust, 1994).

Sprat, Sprattus sprattus, a small, zooplanktivorous clupeid that occurs in high abundance in the southern North Sea, is one of the temporally dominant juvenile species in the GB (ICES, 2007). Sprat spawns pelagic eggs mainly between March and August (Munk, 1993) in a potentially broad range of southern North Sea areas (Aurich, 1941; Johnson and Dawson, 1975; Munk 1991a; Fig. 1). Spawning may be triggered by rising spring temperatures (Alshut, 1988a), since it appears to follow a characteristic spatio-temporal dynamic, commencing earliest in the English Channel region, then progressively later in more eastern areas and latest in the GB. It has been suggested (Alshut, 1988a) but never conclusively demonstrated that these reproductive patterns combined with the residual eastward current in the southern North Sea can result 


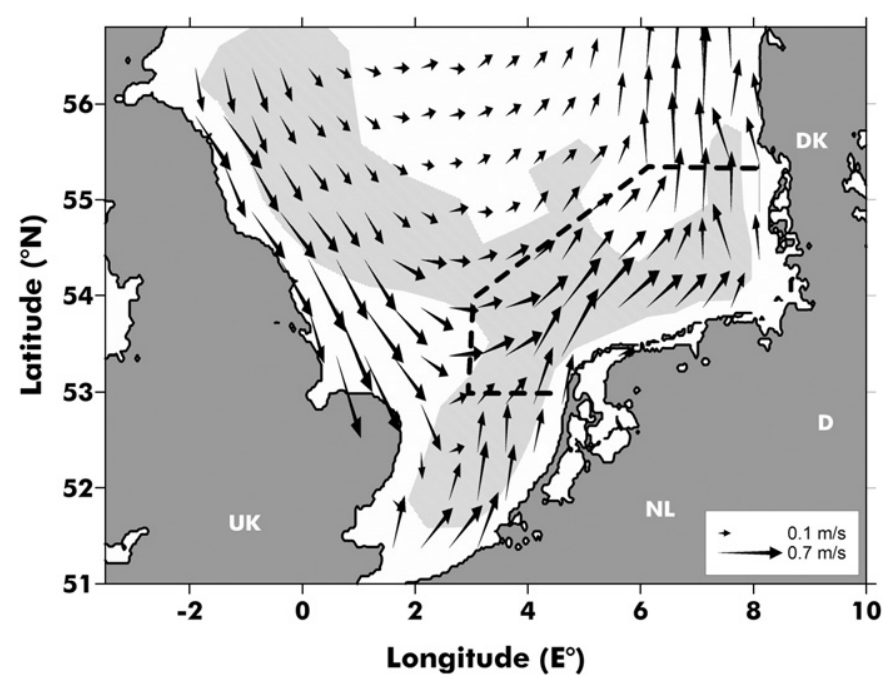

Fig. 1. Map of the North Sea, showing sprat spawning areas (hatched areas, modified after Munk (1991a)) based on historical accounts from Aurich (1941) and Johnson and Dawson (1975). Arrows depict the depth-integrated, mean residual circulation in April/ May 2004 as predicted by the Hamburg Shelf Ocean Model (HamSOM, Pohlmann, 2006). The surveyed area is enclosed by the dashed line. D - Germany, DK - Denmark, NL - Netherlands, UK - Great Britain.

in an aggregation of sprat juveniles from different spawning areas and times in the GB. Such knowledge, however, is a first necessary step towards evaluating the GB's importance as a sprat nursery area. Of equal interest are the processes that shape the population of survivors prior and while juveniles occupy the GB. For example, knowledge about the potential presence, source, and direction of selective mortality, as well as about how environmental conditions influence larval and juvenile growth, is needed to better describe the role of the GB in the pre-recruit part of the sprat life cycle.

Our study was carried out in 2004, and focused on these three major lines of investigation, i.e. (i) the spatial importance of the GB, (ii) potential evidence for selective mortality and (iii) temperaturedependent growth of sprat juveniles in the GB. The three objectives were approached by using otolith microstructure analysis, which has previously proven to be a powerful research tool not only in studies on sprat larvae (e.g., Munk, 1993; Ré and Gonçalves, 1993; Valenzuela and Vargas, 2002), but also on older juveniles (Alshut, 1988a, 1989; Baumann et al., 2006b). This is because sprat form readily discernible, daily otolith increments starting around the time of first feeding (Alshut, 1988b) until at least their first winter (Baumann et al., 2006b). While the number of increments approximates age in days, otolith increment widths are known proxies for somatic growth rates, and hence useful to reconstruct individual growth histories (Stevenson and Campana, 1992).

We first asked whether sprat juveniles that occurred in summer 2004 in the GB were of local and/or external origin (i.e., spawned inside and/or outside the GB, respectively). Our approach was to compare otolith-derived distributions of the juveniles day-of-firstincrement formation (dif, the best available proxy for hatch day) with the abundance of sprat eggs measured monthly during the spawning season in the GB and its adjacent areas (Figs. 1 and 2). Our null hypothesis was that sprat juveniles in the GB were entirely of local origin, which would be indicated if temporal egg abundance patterns in the GB would closely match the dif distribution of juveniles.

Secondly, we studied whether changes in length and growth rate distributions (back-calculated from otoliths) would point to a selective disappearance of certain phenotypes from one survey to the next. Assuming that sampling targeted roughly the same population over time, selection on - say - fast growth (large size-atage) would be distinguishable from random mortality by an upward shift in the lower percentiles of the increment widths distribution from one survey to the next (e.g., Baumann et al., 2003; Shoij and Tanaka, 2006; Robert et al., 2007).

Finally, weekly sea surface temperatures (SST) in the southern North Sea were used as proxies for juvenile thermal histories, which were correlated to back-calculated larval and juvenile growth rates. Temperature is known to be the most important abiotic growth determinant in fish larvae (Heath, 1992) and its intrinsic relationship to growth therefore a key characteristic for a given fish population.

\section{Materials and methods}

\subsection{Juvenile sprat sampling and otolith analysis}

Juveniles were sampled in the GB (i.e., $53^{\circ} 30^{\prime} \mathrm{N}, 6^{\circ} 30^{\prime} \mathrm{E}$ and $55^{\circ} 30^{\prime}$ $\mathrm{N}, 8^{\circ} 30^{\prime} \mathrm{E}$ ) during 3 consecutive surveys in August, September, and October 2004 (Table 1). Two similar pelagic trawl nets (August: EXPO; September/October: 'Juvenile Pelagic Trawl', 16/10 mm stretched cod end meshes, respectively) were deployed and assumed to representatively catch juvenile fish $\geq 5 \mathrm{~cm}$ TL (according to selectivity estimates by Bethke et al., 1999). Hauls were conducted at daylight hours, lasted approximately $30 \mathrm{~min}$, and covered the depth strata where hydroacoustic backscatter indicated the presence of fish. From each catch that contained a sufficient amount of sprat, an approximately $10 \mathrm{~kg}$ sub-sample was stored at $-20^{\circ} \mathrm{C}$.

In the laboratory, TL and SL (standard length) of sprat juveniles were measured to the nearest $\mathrm{mm}$, prior to removal of the sagittal otoliths. Because of earlier age readings, specimens $>90 \mathrm{~mm}$ were considered to be age 1 or older (J-P Herrmann, unpublished data; Munk, 1991b). Otolith preparation and microstructure analysis followed the methods described in Baumann et al. (2006b). Briefly, individually mounted otoliths (Crystallbond ${ }^{\circledR} 509$ thermoplastic glue) were manually polished from both sides with a $3 \mu \mathrm{m}$ lapping film (266x Imperial PSA 3M ${ }^{\circledR}$ ) until all micro-increments were sufficiently visible along the core-postrostrum axis. An image analysis software (ImagePro 4.5.1) was then used to count and measure $(\mu \mathrm{m})$ individual increments in multi-frame digital images, which were taken under $400 \times$ magnification with a high-resolution digital camera (Leica ${ }^{\circledR}$ DC300). Sufficient ageing precision has previously been confirmed via within-and across-reader comparisons as reported by Baumann et al. (2006b). A total of 193 individuals from 29 hauls were available for the present analysis (Table 1 ).

An iridescent check-mark, found at an average distance of $8.3 \mu \mathrm{m}$ $(\mathrm{SD}=1.2 \mu \mathrm{m})$ from the otolith core, was assumed to correspond to the day of hatch. The day of first increment formation (dif) was derived by subtracting the number of all increments (hatch check to postrostrum) from the sampling date. No correction was made for the difference between hatch date and dif ( 5-10 days, Alshut (1988b), Petereit et al. (2008)), given the unknown thermal history of sprat juveniles during their egg and yolk sac stage.

The average juvenile length distribution of each survey (= average of each hauls relative distribution for specimens $<90 \mathrm{~mm} \mathrm{TL}$ ) was used to correct for potential over-or underrepresented length classes in the sub-samples selected for otolith analyses. For every $5 \mathrm{~mm}$ TL class, the length frequency from the otolith sample was divided by the corresponding frequency from the field. This ratio was then assigned as a weighing factor to each analyzed specimen and used later for correction of TL, dif, and increment width distributions. Weighing factors at the extremes of the distributions ranged between 0.08 (too many otoliths read in a length class) and 4.2 (too few otoliths read), whereas for the main length classes $(55-<85 \mathrm{~mm} \mathrm{TL})$ they were close to 1 (mean $=1.08)$.

\subsection{Objective 1: Local vs. external origin of sprat juveniles}

Here, otolith-derived age data of juveniles (dif-distributions) were contrasted with spatio-temporal patterns in sprat egg and larval 


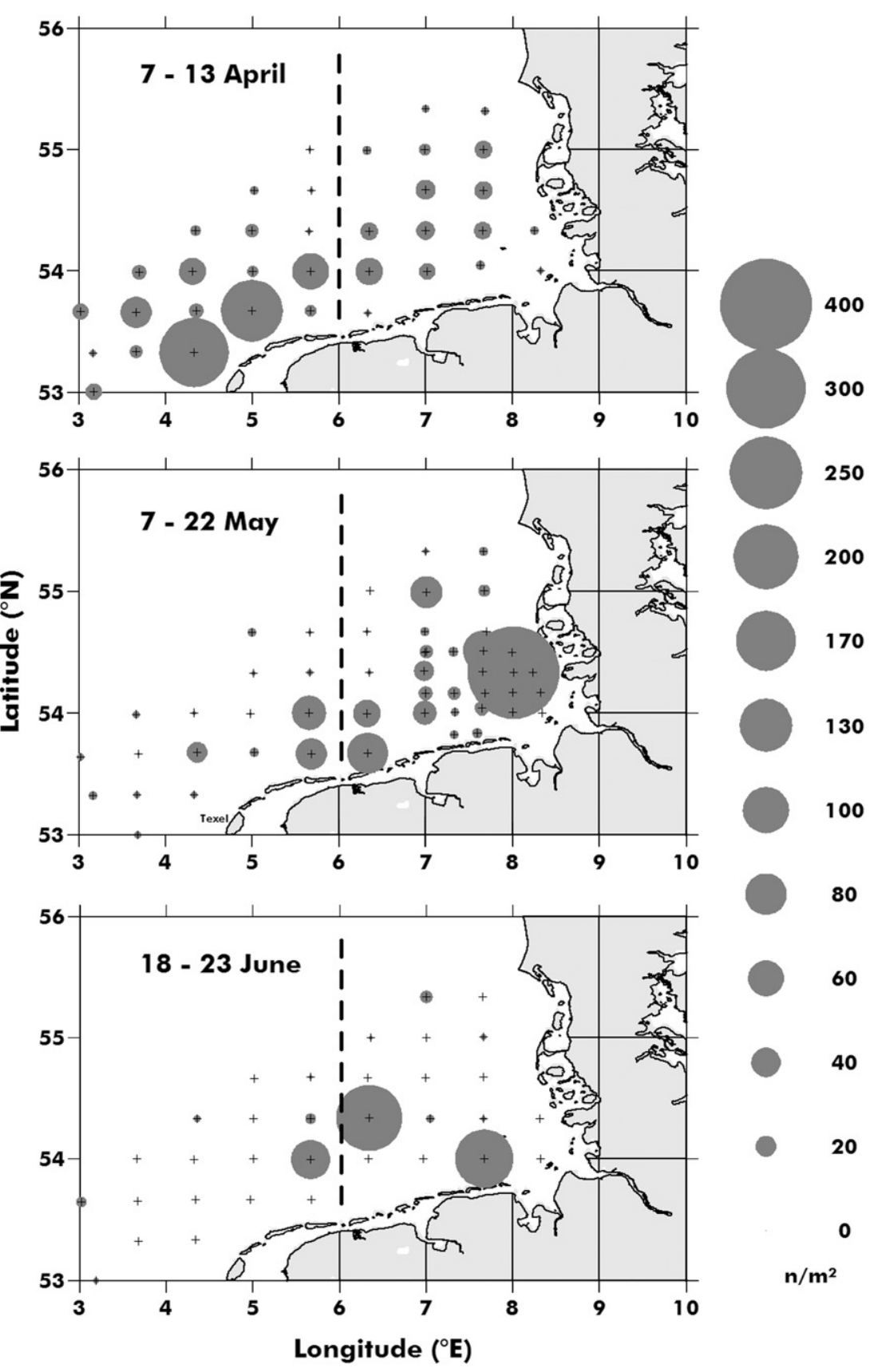

Fig. 2. Sprattus sprattus. Egg abundance (combined stages Ia, Ib, and II) in the survey area (crosses depict grid stations) in April, May, and June 2004 (egg abundance was zero AugustOctober). Areas east and west of $6^{\circ} \mathrm{E}$ (dashed line) are referred to as in-and outside the German Bight, respectively.

production. Sprat eggs were collected between April and October 2004 during 6 monthly GLOBEC surveys that covered the GB and its adjacent areas with a regular grid of $35-50$ stations (Fig. 2). A bongo net equipped

\section{Table 1}

Number of pelagic hauls conducted in August, September and October 2004, hauls in the German Bight (North Sea) containing sufficient sprat juveniles $(<90 \mathrm{~mm} \mathrm{TL}$ ) for analysis, sampling times, number of analysed individuals, and basic information on TL ( $\mathrm{mm}$ ), age (days after dif) and dif (day of first increment formation) for each survey.

\begin{tabular}{llll}
\hline & August & September & October \\
\hline Hauls (all) & 44 & 20 & 11 \\
Hauls (juv sampled) & 13 & 7 & 9 \\
Sampling period & $9-18.8$. & $7-10.9$. & $14-15.10$. \\
Otoliths & 67 & 60 & 66 \\
Mean $T L(S D)$, mm & $70.7(7.6)$ & $75.2 \mathrm{~d}(10.3)$ & $74.8 \mathrm{~d}(8.0)$ \\
Mean age (SD), days & $123(19.0)$ & $132(18.7)$ & $161(18.5)$ \\
Mean dif (SD), date & 14 April (19.1d) & 30 April $(18.7 \mathrm{~d})$ & 7 May $(18.4 \mathrm{~d})$ \\
\hline
\end{tabular}

with a $335 \mu \mathrm{m}$ mesh section and a General Oceanics ${ }^{\circledR}$ flow meter was double-obliquely towed at a ship speed of 3 knots between the surface and $5 \mathrm{~m}$ above the bottom. Bongo samples were immediately preserved in $4 \%$ buffered formaldehyde/seawater solution for later analysis. In the laboratory, fish eggs were identified to species level, and sprat eggs were staged following the 5 stage system of Thompson et al. (1981). Taking into account the filtered volume and the water depth, stage-specific sprat egg abundance was then estimated as numbers per $\mathrm{m}^{2}$ sea surface. For our comparison, we defined all grid stations east and west of $6^{\circ} \mathrm{E}$ as in-and outside the GB, respectively (Fig. 2).

Additional data on small larvae abundance $(<10 \mathrm{~mm} \mathrm{SL})$ in the inner GB were available from ichthyoplankton samples taken 3-5 times per week in 2004 at the monitoring station 'Helgoland Roads' $\left(54^{\circ} 11.18^{\prime} \mathrm{N}\right.$ and $07^{\circ} 54^{\prime} \mathrm{E}$, depth $=10 \mathrm{~m}$, for further details refer to Malzahn and Boersma, 2007). A Cal-COFI ring trawl $(\varnothing=100 \mathrm{~cm})$ equipped with a $500 \mu \mathrm{m}$ mesh net and a flow meter was double 
obliquely deployed for $15 \mathrm{~min}$ from a small research vessel. The unpreserved samples were brought to the nearby institute, and larval fish were immediately sorted under a stereo microscope (Olympus B061) and classified to species level according to Halbeisen (1988). Sprat larvae abundance was later normalized to individuals per $\mathrm{m}^{3}$.

\subsection{Objective 2: Potential selective mortality}

Here we compared otolith microstructural patterns between the 3 consecutive trawl surveys (August, September, October 2004) using two different approaches. In the first approach, all juvenile TL's were individually back-calculated to 8 August and 6 September 2004 (beginning of the first and second survey, respectively) using biological intercepts for length (i.e., $5.5 \mathrm{~mm}$; Shields, 1989) and otolith size (i.e., distance core-first increment). The biological intercept method is independent of the slope in the overall otolith-fish size regression, but assumes linearity in individual otolith-fish size trajectories (Campana, 1990). To avoid bias by potential survey differences in temporal origin (dif), the comparisons of backcalculated TL were done separately for each 14-day dif period that contained a minimum of 3 specimens. 1-way ANOVAs of TL with Scheffe post-hoc tests were used to detect significant differences $(P<0.05)$ between the 3 ( 8 August) or 2 ( 6 September) surveys.

In a second approach, we studied survey-to-survey changes in the upper and lower percentiles (90th and 10th percentiles, respectively) of increment widths distributions (i.e., the variability in growth phenotypes). Given that both the mean and variance of otolith increment widths strongly co-vary with age (Pepin et al., 2001), distributions were compared between surveys only after increment widths were standardized to zero mean and unit variation

$z_{i j}=\left(x_{i j}-x_{j}\right) s_{j}^{-1}$

where $x_{i j}$ is the increment width of the individual $i$ at age $j$, and $x_{j}$ and $s_{j}$ are the mean and standard deviation of increment widths at age $j$, respectively, for all specimens included. Only specimens with difs between 29 March and 23 May 2004 were compared, since this was the range common to all three surveys. Provided that the 3 surveys sampled the same juvenile population, we expected that selective mortality would be apparent from a narrowing of the distribution with consistent upward shifts in the lower percentile or downward shifts in the upper percentile indicating selection for fast or slow growth, respectively.

\subsection{Objective 3: Temperature-dependent growth}

We obtained sea surface temperatures (SST) for 2004 in the North Sea from the German "Bundesamt für Seeschifffahrt und Hydrographie" (www.bsh.de). The data are a combination of in situ measurements and observations of the NOAA 12 and 16 satellites with an initial spatial resolution of $1.1 \mathrm{~km}$. Raw data are routinely pre-processed with a multichannel SST-algorithm and then provided to users as weekly averages of SST on a regular $20 \times 20 \mathrm{~km}$ grid encompassing the area between $7^{\circ} \mathrm{W}$ to $13^{\circ} \mathrm{E}$ and $49.5^{\circ} \mathrm{N}$ to $62^{\circ} \mathrm{N}$. To derive a proxy for the temperature history of sprat juveniles we restricted the data to the $\mathrm{GB}\left(6^{\circ} \mathrm{E}\right.$ to $9^{\circ} \mathrm{E}$ and $53.5^{\circ} \mathrm{N}$ to $56{ }^{\circ} \mathrm{N}$ ), assuming that (i) individuals originated from this area and stayed in it until sampling and (ii) that vertical temperature differences in this shallow region are too temporally unstable to be of importance (Pingree and Griffiths, 1978). However, even if sprat originated from an area adjacent to the GB (e.g., more from south-west, given the general counter-clockwise circulation pattern in the North Sea), the bias was assumed to be negligible because seasonal temperature fluctuations $\left(S S T_{\min } / S S T_{\max }=4.5{ }^{\circ} \mathrm{C} / 20.0{ }^{\circ} \mathrm{C}\right)$ exceeded the spatial temperature variability by far (within the entire North Sea grid, the weekly standard deviation of SST ranged between $0.92{ }^{\circ} \mathrm{C}$ and $2.20^{\circ} \mathrm{C}$ ). Daily SST values for the GB were derived by linear interpolation between weeks.

To study the influence of temperature on juvenile sprat growth histories, we estimated daily somatic growth rates $\left(G R_{\mathrm{s}}\right)$ from individually back-calculated standard lengths (biological intercept method) and then averaged these over 12 different periods after the day of first increment formation (i.e., 10, 20, 30... 120 days after dif). The relationship between mean $G R_{\mathrm{S}}$ and corresponding average SST was studied for each period by linear regression analysis.

\section{Results}

3.1. Length distributions of GB sprat in August, September, and October

The August length distribution was clearly bi-modal, with 0 groups and age $1+$ groups being most abundant between $65-75 \mathrm{~mm}$ TL and 100-110 mm TL, respectively (Fig. 3). During the September survey, 0-group modal length had shifted to the 80-85 mm TL class, while adult sprat peaked around $110-115 \mathrm{~mm}$ TL. On its lower end, the September length distribution was indicative of a smaller, second cohort present in the GB with modal lengths of 60-65 mm TL (Fig. 3). October catches consisted almost entirely of juveniles $<90 \mathrm{~mm}$ TL (96\%). The October length distribution also suggested the presence of yet another, much smaller sprat cohort (35-50 mm TL, Fig. 3) in the study area. Mean $\pm S D$ of juvenile lengths increased from August to September from $70.7 \pm 7.6 \mathrm{~mm}$ to $75.2 \pm 10.3 \mathrm{~mm} \mathrm{TL}$, but decreased until October again to $74.8 \pm 8.0 \mathrm{~mm}$ TL (Table 1 ).

\subsection{Objective 1: Local vs. external origin of sprat juveniles}

Sprat eggs occurred in the ichthyoplankton samples only during the first 3 surveys in April, May, and June 2004. Despite the high
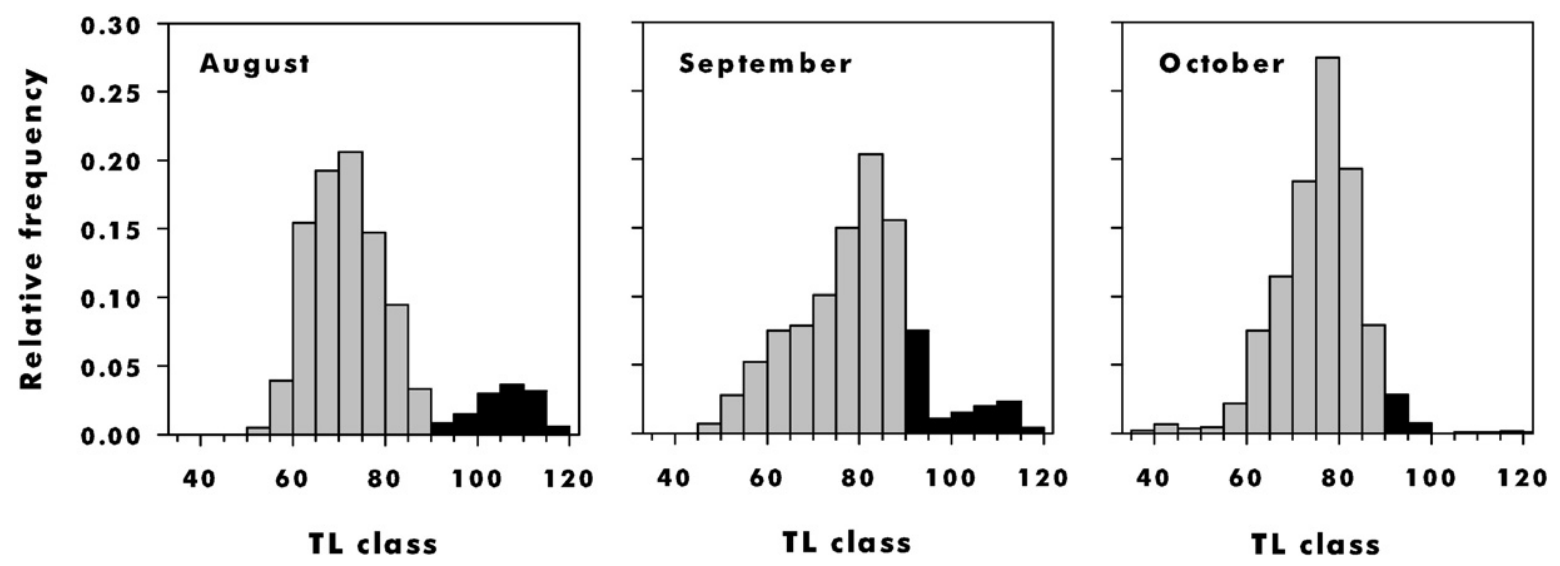

Fig. 3. Sprattus sprattus. Relative total length distributions in August, September, and October in the GB. A TL of 90 mm had a priori been assumed to separate age0 (grey bars) from age $1+$ individuals (black bars). 
variability between stations, the distribution showed a distinct spatiotemporal pattern (Fig. 2). In April, all egg stages were concentrated outside the GB (i.e., west of $6^{\circ} \mathrm{E}$ ) mainly at two stations off the Dutch
Wadden Sea (Fig. 2). An eastward shift of egg abundance into the GB was then apparent in the May and June samples. Highest concentrations of up to 400 eggs per $\mathrm{m}^{2}$ (stages I + II) were found in May in two
Eggs outside GB $\left(<6^{\circ} \mathrm{E}\right)$
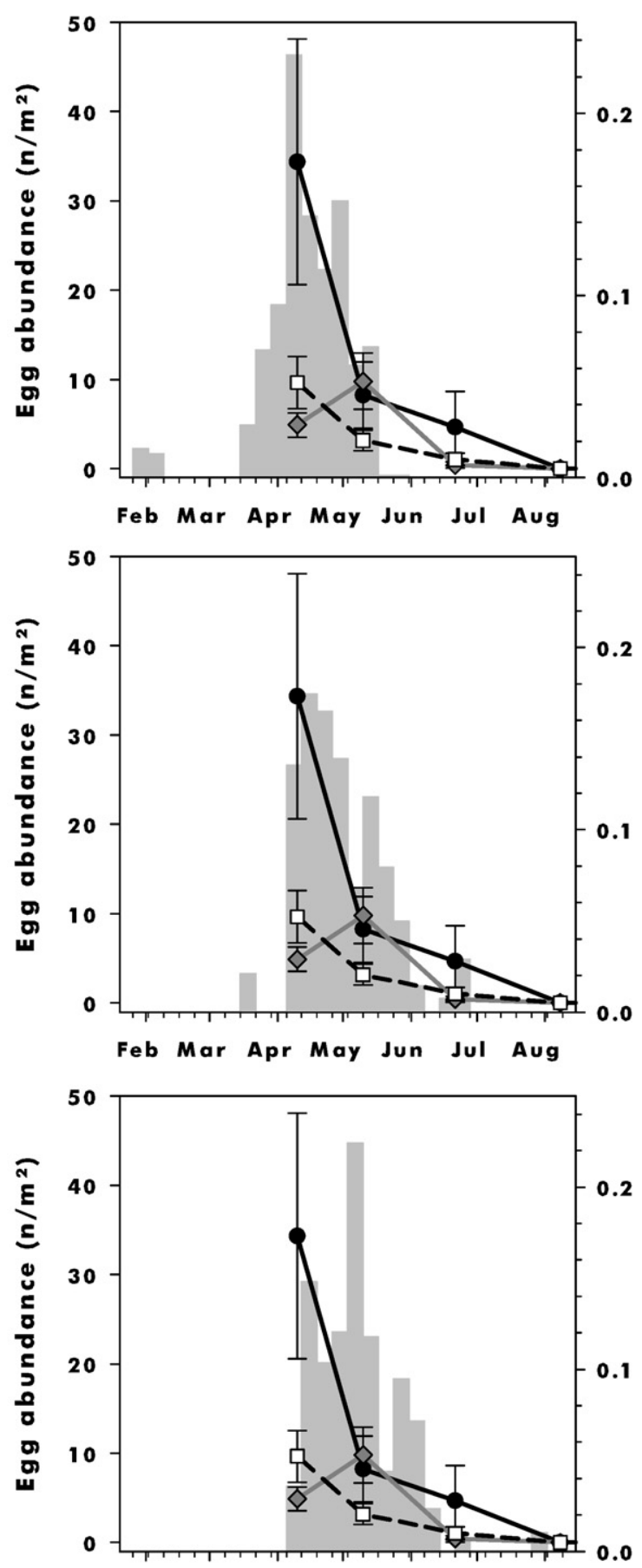

Feb Mar Apr May Jun Jul Aug
Eggs inside GB $\left(>6^{\circ} \mathrm{E}\right)$
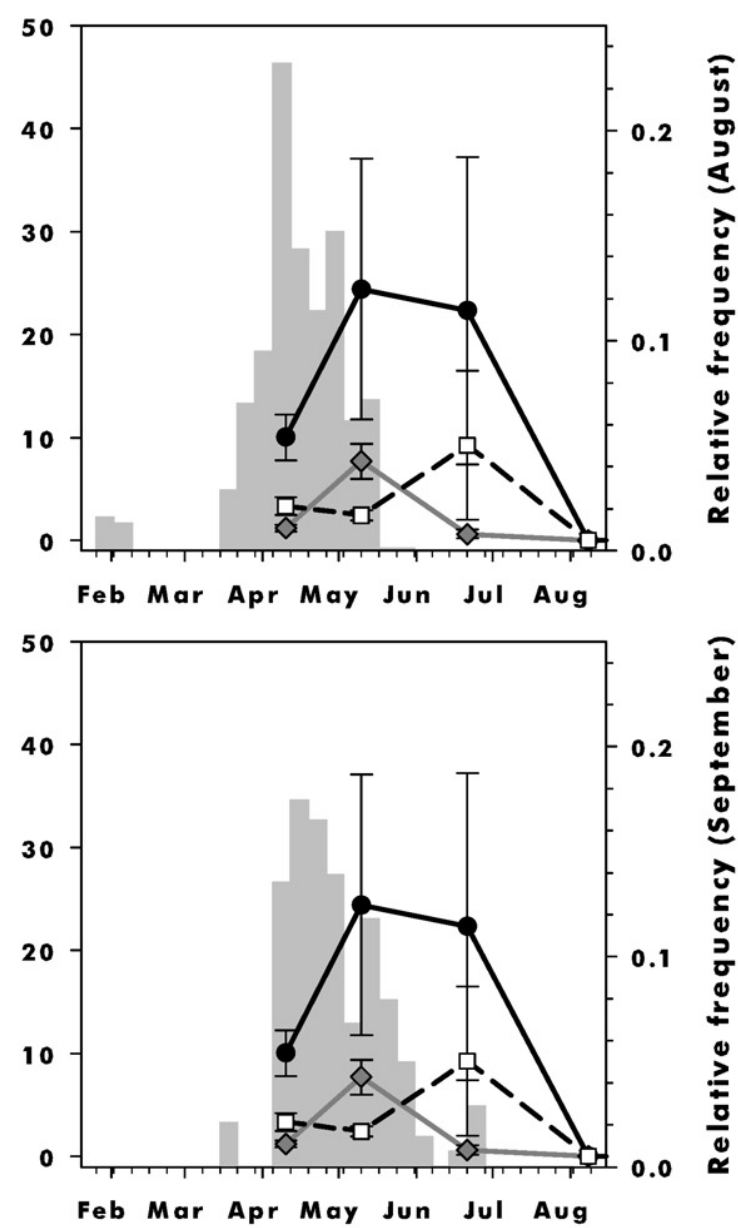

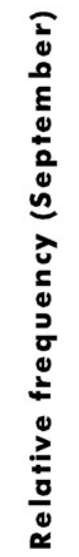

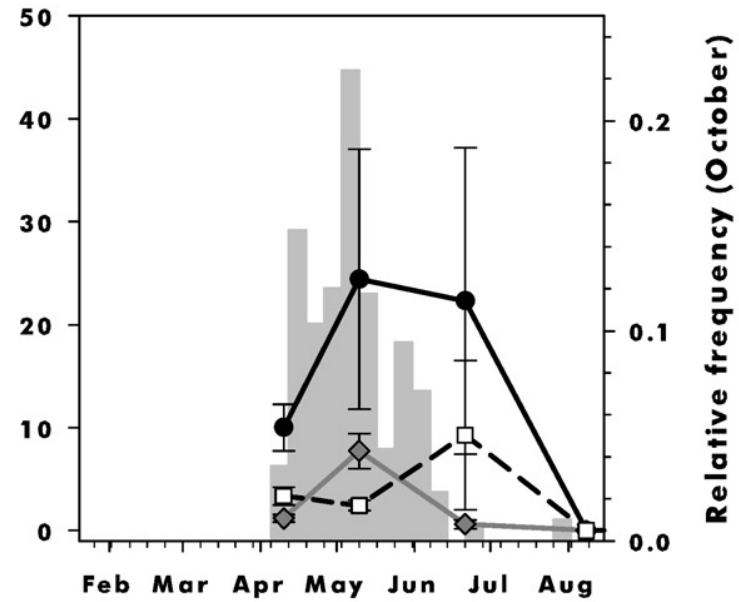

2004

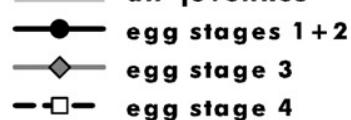

Fig. 4. Sprattus sprattus. Comparison between dif distributions of juveniles (grey bars) caught in August (upper panels), September (middle panels), and October 2004 (lower panels) in the GB and mean ( \pm 1 s.e.) seasonal abundance of egg stages $1+2$ (black circles), 3 (grey diamonds), and 4 (white squares) out-(left panels) and inside (right panels) the GB. 


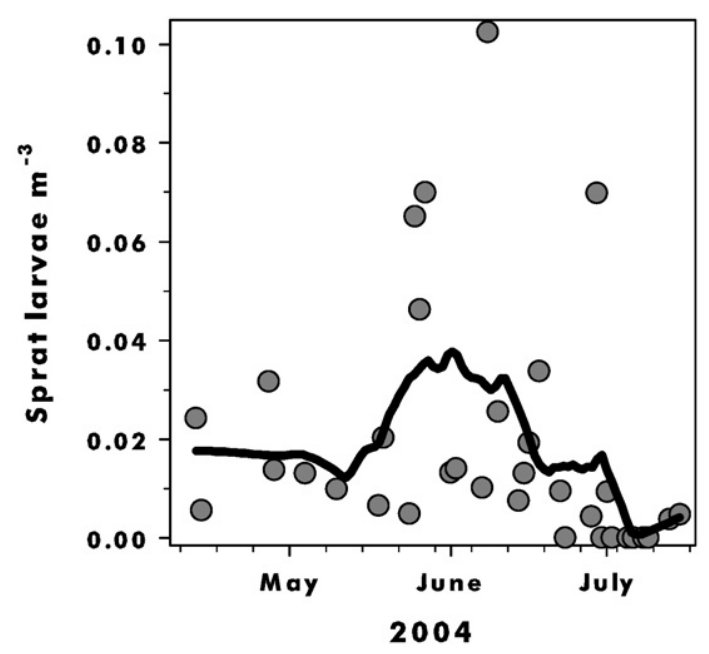

Fig. 5. Sprattus sprattus. Seasonal abundance of small larvae $(<10 \mathrm{~mm} \mathrm{SL})$ at the monitoring station 'Helgoland Roads' ( $\left.54^{\circ} 11.18^{`} \mathrm{~N}, 7^{\circ} 54^{\circ} \mathrm{E}\right)$, fitted with a local smoothing function (Loess, SigmaPlot 10.0).

cores, just north-east of Helgoland and to a lesser extent at stations close to the Dutch and German Wadden islands. Two similar cores of egg abundance also appeared in June in the GB (Fig. 2).

A large fraction of juvenile difs pre-dated the major sprat spawning effort in the GB considerably. Individuals sampled in August originated mainly from mid-March to mid-May (mean $\pm S D=14$ April \pm 19.1 days), with the notable exception of 2 juveniles with difs on 29 January and 5 February 2004 (Fig. 4). Windows of origin remained in April/May for juveniles from the September and October surveys, although mean difs shifted to 30 April ( \pm 18.7 days) and 7 May ( \pm 18.4 days), respectively. In October, 4 exceptionally young specimens with $<50 \mathrm{~mm}$ TL originated from the last week of July (Fig. 4).

Comparing both patterns, the seasonal sprat egg production outside the GB (i.e., west of $6^{\circ} \mathrm{E}$ ) corresponded more closely to the temporal origin of juveniles sampled between August and October 2004 (Fig. 4). Particularly the large number of juveniles born in April did not match the negligible number of sprat eggs observed in April inside the GB (Fig. 4). The occurrence of small (i.e., few days post hatch) sprat larvae at the monitoring station 'Helgoland Roads' showed a corroborating seasonal pattern (Fig. 5). Despite a very high day-to-day variability in larval abundance, peak values of up to 0.1 larvae per $\mathrm{m}^{3}$ were only observed between mid-May and the end of June. These larvae were thus presumably born later than the majority of juveniles sampled between August-October 2004.

\subsection{Objective 2: Potential selective mortality}

On 8 August 2004, sprat juveniles caught during the 2nd and 3rd survey (September and October) had consistently lower back-calculated lengths than juveniles caught during the first survey in August (Table 2).
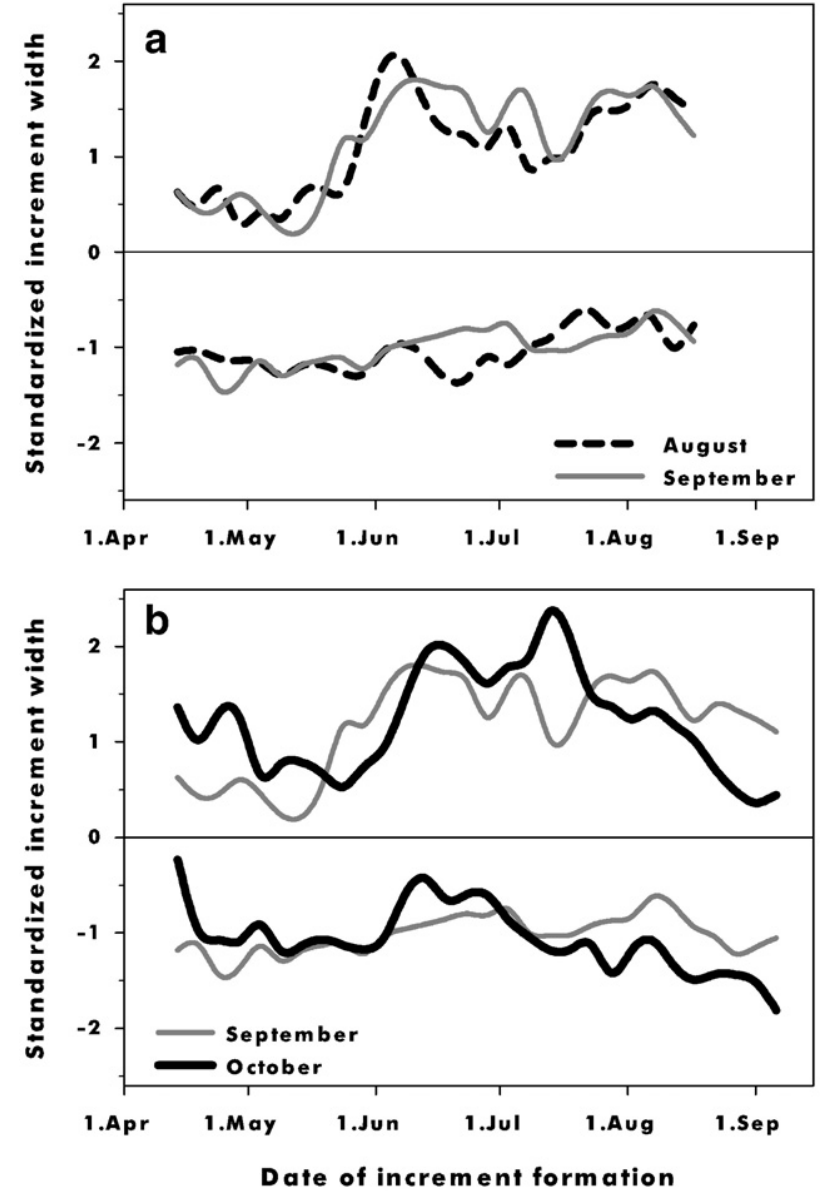

Fig. 6. Sprattus sprattus. 5 day running average of the upper and lower percentiles (10th and 90th, respectively) of distributions of standardized increment width (agedetrended otolith growth rates) for juveniles sampled in August and September (a) and September and October 2004 (b) in the GB.

Similarly, on 6 September, juveniles sampled during the 3rd survey were significantly $(P<0.01)$ smaller than those sampled during the 2nd survey (Table 2). This indicated a selective removal of larger sizes-at-age from one survey to the next. On the other hand, selective mortality alone could not explain the patterns in the distributions of age-detrended (standardized) otolith growth rates. There were no major and consistent differences between the 10th and 90th percentiles of the August vs. September distributions, thus indicating random mortality (Fig. 6). More importantly, the 10th and 90th percentiles of the October population started to decrease at the end of June and mid-July, respectively, and stayed consistently below the September percentiles thereafter. Thus, relatively slow growing phenotypes that were absent in September, appeared in the distribution in October which likely resulted in the observed smaller mean sizes-at-age (Fig. 6).

Table 2

Sprattus sprattus.

\begin{tabular}{|c|c|c|c|c|c|c|c|c|c|c|}
\hline \multirow{3}{*}{ dif interval } & \multicolumn{6}{|c|}{ TL (mm) back-calculated to 8 August 2004} & \multicolumn{4}{|c|}{ TL (mm) back-calculated to 6 September 2004} \\
\hline & \multicolumn{2}{|l|}{ August survey } & \multicolumn{2}{|c|}{ September survey } & \multicolumn{2}{|l|}{ October survey } & \multicolumn{2}{|c|}{ September survey } & \multicolumn{2}{|c|}{ October survey } \\
\hline & $\mathrm{TL} \pm \mathrm{SD}$ & $N$ & $\mathrm{TL} \pm \mathrm{SD}$ & $N$ & $\overline{\mathrm{TL}} \pm \mathrm{SD}$ & $N$ & $\mathrm{TL} \pm \mathrm{SD}$ & $N$ & $\overline{\mathrm{TL}} \pm \mathrm{SD}$ & $N$ \\
\hline 29 March-11 April & $71.6 \pm 6.5$ & 22 & $71.3 \pm 3.1$ & 8 & 60.4 & 2 & $84.8 \pm 5.2$ & 8 & 70.5 & 2 \\
\hline 12-25 April & $66.2 \pm 4.7^{(0)}$ & 17 & $65.5 \pm 5.6$ & 19 & $61.6 \pm 4.0^{(\mathrm{A})}$ & 17 & $80.3 \pm 5.3^{(0)}$ & 19 & $72.9 \pm 4.7^{(\mathrm{S})}$ & 17 \\
\hline 26 April-9 May & $61.5 \pm 4.3^{(0)}$ & 14 & $58.8 \pm 6.6^{(0)}$ & 12 & $53.2 \pm 5.6^{(\mathrm{A}, \mathrm{S})}$ & 23 & $73.6 \pm 8.0^{(0)}$ & 12 & $66.0 \pm 6.3^{(\mathrm{S})}$ & 23 \\
\hline 10-23 Мау & $53.3 \pm 1.8$ & 5 & $50.4 \pm 4.7$ & 11 & $48.9 \pm 5.1$ & 11 & $66.6 \pm 6.2$ & 11 & $64.3 \pm 6.7$ & 11 \\
\hline 24 May-6 June & & & $42.2 \pm 5.3$ & 4 & $42.4 \pm 4.3$ & 11 & $59.0 \pm 5.7$ & 4 & $58.2 \pm 6.6$ & 11 \\
\hline
\end{tabular}

Back-calculated mean TL \pm 1 SD of juveniles with similar temporal origin (14-d dif period) caught during August, September, and October 2004 in the GB. The two dates 8 August and 6 September correspond to the beginning of the September and October survey, respectively.

(A), (S), (O) difference significant $(P<0.05)$ against August, September, October, respectively. 


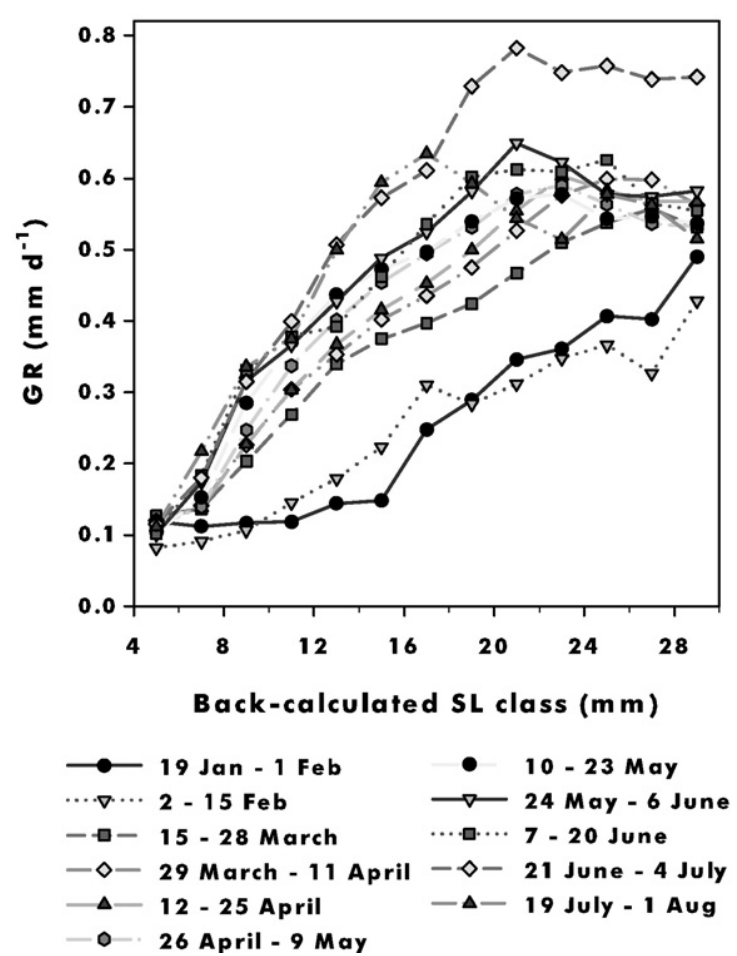

Fig. 7. Sprattus sprattus. Mean back-calculated standard length growth rates $\left(G R_{s}\right)$ in relation to size ( $2 \mathrm{~mm} S L$-class) and the time of first increment formation (bi-weekly dif intervals) for juveniles sampled between August and October 2004 in the GB (North Sea). For clarity, the graph was restricted to $S L$-classes $<30 \mathrm{~mm}$.

\subsection{Objective 3: Temperature-dependent growth}

Otolith-derived standard length growth rates $\left(G R_{\mathrm{s}}\right)$ of sprat pooled across surveys varied with back-calculated SL and the time of first increment formation. Until about $30 \mathrm{~mm} \mathrm{SL}, G R_{\mathrm{S}}$ increased continuously from initially $0.08-0.12 \mathrm{~mm} \mathrm{~d}^{-1}$ to $0.49-0.74 \mathrm{~mm} \mathrm{~d}^{-1}$ (Fig. 7), except for the two earliest born individuals that reached similarly high $G R_{\mathrm{s}}$ much later, at approximately $57 \mathrm{~mm} \mathrm{SL}$ (Fig. 8). The initial increase in $G R_{s}$, presumably corresponding to the larval stage, was consistently higher for individuals born later in the season. Sprat that

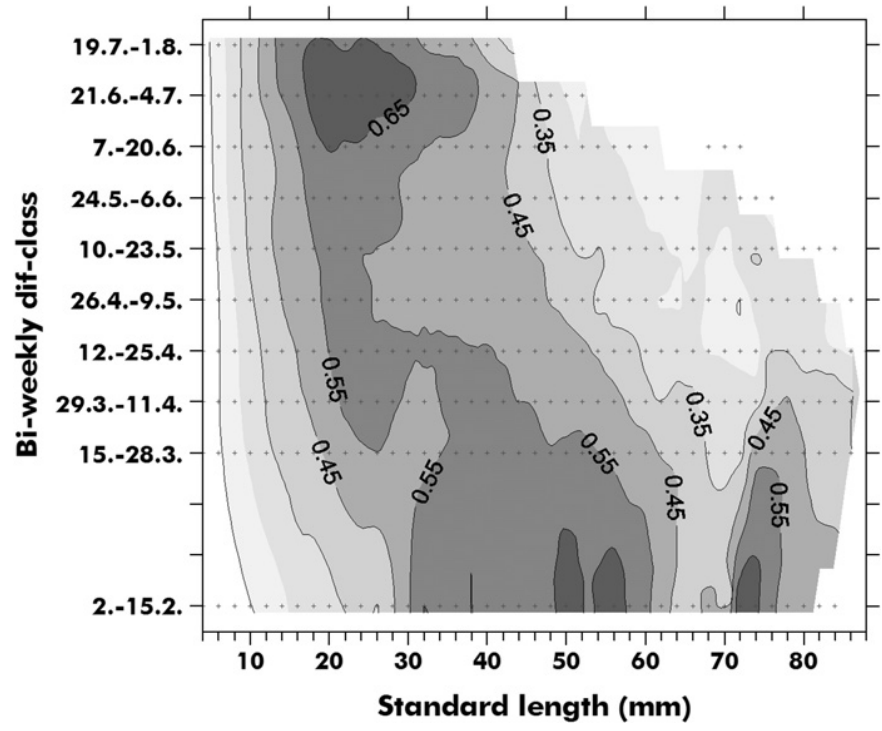

Fig. 8. Sprattus sprattus. Contour plot of mean back-calculated standard length growth rates $\left(G R_{s}\right)$ in relation to size ( $2 \mathrm{~mm} S L$-class) and the time of first increment formation (bi-weekly dif intervals) for pooled juveniles sampled August- October 2004 in the GB. formed their first increment between 15 and 28 March 2004 achieved a back-calculated $G R_{\mathrm{s}}$ of $0.4 \mathrm{~mm} \mathrm{~d}^{-1}$ at about $20 \mathrm{~mm} \mathrm{SL}$, whereas those with difs between 21 June and 4 July grew already as fast at about
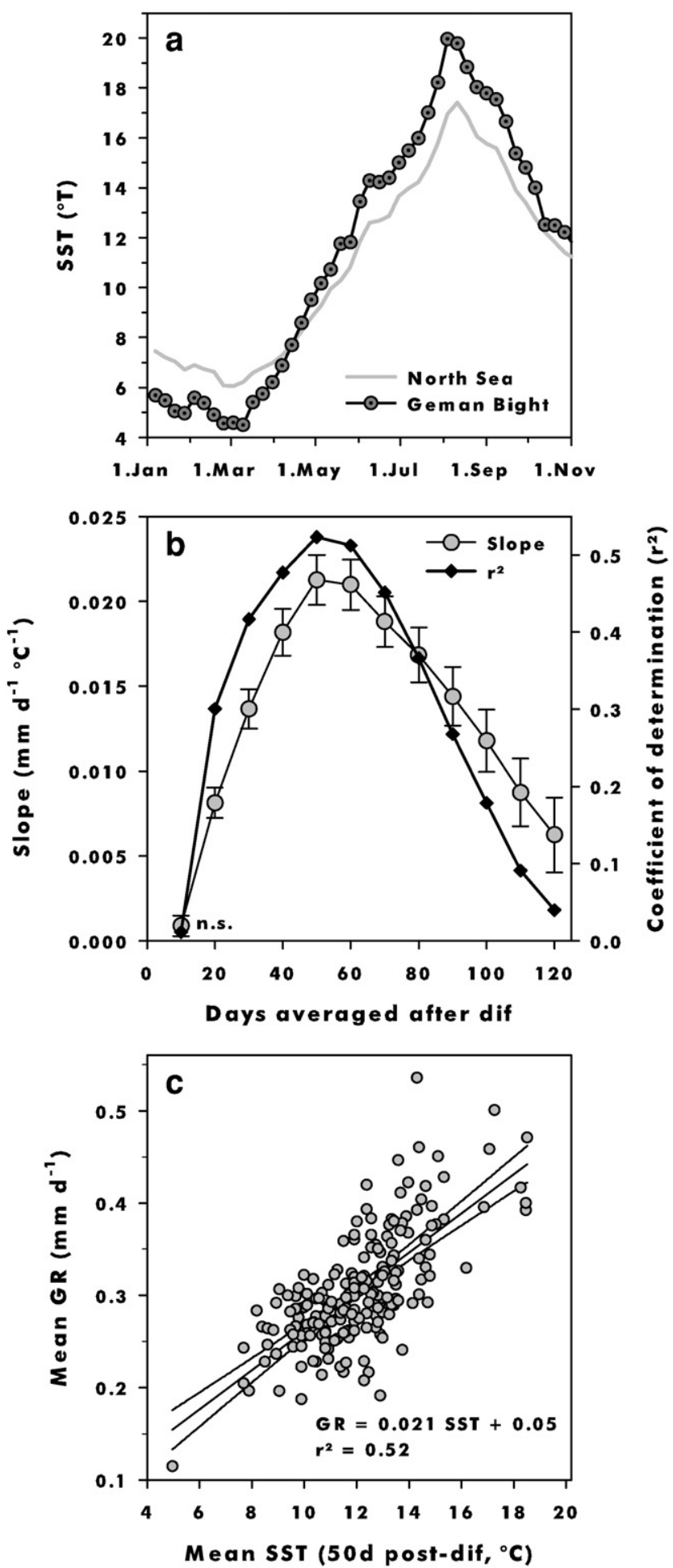

Fig. 9. Sprattus sprattus. Temperature dependence of standard length growth rates $\left(G R_{\mathrm{s}}\right)$ for juveniles sampled between August- October 2004 in the GB (North Sea). (a) Mean, weekly sea surface temperature $\left(S S T,{ }^{\circ} \mathrm{C}\right)$ in the $\mathrm{GB}\left(6-9{ }^{\circ} \mathrm{E}, 53.5-56{ }^{\circ} \mathrm{N}\right.$, circles) and the entire North Sea $\left(-7-13{ }^{\circ} \mathrm{E}, 49.5-62{ }^{\circ} \mathrm{N}\right.$, grey line). (b) Slopes and correlation coefficients of linear regressions of $G R_{S}$ on SST for periods of $10,20,30, \ldots, 120$ days after first increment formation. Except for the first period (10d), all regressions were significant $(P<0.05)$, but the temperature impact is strongest during the initial 50 days. (c) Mean $G R_{\mathrm{s}}$ of juveniles during their initial 50 days after first increment formation in relation to mean SST during the corresponding 50 -d period. 
$12 \mathrm{~mm} \mathrm{SL}$ (Fig. 7). However, faster $G R_{\mathrm{S}}$ during the initial (larval) period was consistently followed by more rapidly declining, juvenile $G R_{\mathrm{S}}$ after peak growth. For juveniles originating from March, average $G R_{\mathrm{s}}$ declined to $0.4 \mathrm{~mm} \mathrm{~d}^{-1}$ at about $79 \mathrm{~mm} \mathrm{TL}$, while those in the latter dif-interval (21 June-4 July) had already fallen back to this rate at around $57 \mathrm{~mm}$ TL (Fig. 8).

SST in the GB continuously increased from $4.6{ }^{\circ} \mathrm{C}$ during the last week in February to $20.0^{\circ} \mathrm{C}$ early in August 2004 (Fig. 9a), entailing a progressively warmer environment for later-in-the-season born sprat offspring. Linear regressions between mean $G R_{\mathrm{s}}$ and mean SST for periods of 10 to 120 days after dif were all positive and significant $(P<0.05, n=193)$, however, both the slopes and coefficients of correlation $\left(r^{2}\right)$ varied with period length (Fig. 9b). The strongest correlation between SST and $G R_{\mathrm{S}}$ was found during the initial 50 days after $\operatorname{dif}\left(r^{2}=0.52\right)$, thereby roughly corresponding to the larval stage of sprat. The slope of this linear regression was $0.021 \mathrm{~mm} \mathrm{~d}^{-1}{ }^{\circ} \mathrm{C}^{-1}$, suggesting that a temperature difference of e.g. $5{ }^{\circ} \mathrm{C}$ experienced by two individuals during their initial 50 days would result in a standard length difference of $5.25 \mathrm{~mm}$ (Fig. 9c).

\section{Discussion}

Our study clearly showed that the German Bight acts as a nursery area not only for locally produced sprat juveniles, but also for offspring originating from a much wider range of potential spawning grounds in the southern North Sea. This was apparent from the mis-match between otolith-derived distributions of juvenile temporal origin and spatiotemporal patterns in sprat egg abundance during the spawning season 2004. We found that a considerable proportion of juveniles originated from April, corresponding to a high spawning activity west of the GB, whereas inside the GB notable spawning only occurred in May/June. These two months are known as the main spawning season for sprat in the GB (Wahl and Alheit, 1988; Munk, 1993; Bartsch and Knust, 1994). In North Sea areas west of the GB, however, spawning may regularly commence earlier because temperatures rise earlier in spring. Alshut (1988a) suggested that sprat begin to spawn at a threshold of $6{ }^{\circ} \mathrm{C}$, which can already be reached in January in the English Channel and then progressively later in more north-eastern areas. Satellite-based SST data confirmed this pattern for 2004. We note that egg abundance west of the GB was already maximal during our first survey in 2004, thus suggesting that spawning had begun there even prior to April. Otolith data supported this, because some of the specimens caught in August in the GB originated from March, the oldest two even from January/February 2004, corroborating findings by Alshut (1988a). For juveniles sampled in September, we noticed a suspicious gap in the dif distribution around the end of March, possibly because our assumed cut-off point at $90 \mathrm{~mm}$ TL excluded some of the few largest/oldest juveniles in the 90-95 mm TL class. Our assumption was based on earlier age readings (J-P Herrmann, unpublished data) and reasonable for both the August and October surveys. We note that inclusion of 90-95 $\mathrm{mm}$ TL specimens (which were unfortunately no longer available for analysis), would likely have strengthened our main conclusion, i.e., that a large fraction of juveniles were born prior to the onset of spawning inside the GB and therefore of external origin. Overall, the range of hatch dates observed in this study for juveniles from the GB (i.e., end of January - end of July) was truly remarkable, consistent with earlier reports (Alshut, 1988a; Knust, AWI Bremerhaven, unpublished data), and much larger than windows of temporal origin inferred, for example, for sprat from the western or central Baltic Sea (Baumann et al., 2008). This indicates that in the southern North Sea sprat offspring from very different months (and areas, by implication) can encounter suitable conditions to survive and may temporarily aggregate in the GB (Alheit et al., 1987; Valenzuela et al., 1991).

The general, counter-clockwise circulation in the North Sea (Otto et al., 1990) is a plausible mechanism, how sprat offspring from other spawning areas may reach the GB. Mean residual (i.e., without tidal) currents in April/May 2004 in the southern North Sea, estimated with the 3-D Hamburg Shelf Ocean Model (Pohlmann, 2006), were consistently above $0.2 \mathrm{~m} \mathrm{~s}^{-1}$ (Fig. 1), a value sufficient for a passive particle from the English Channel to reach the GB within one month. To infer the spatial origin and likely drift routes of juveniles, some authors have applied hydrodynamic models combined with Lagrangian particle back-tracking (e.g., Allain et al., 2003). This was not attempted here because of the relatively large sizes of our juveniles (actively swimming, schooling fish are unlikely to 'behave' like passive particles) and their unresolved time of arrival in the GB prior to catch.

If sprat offspring from different areas and spawning times passively and/or actively reach the GB in spring/summer, one should expect to find multiple juvenile cohorts present in the area at a given time. This was indeed indicated by juvenile length distributions in our September and October catches, even though some of the cohorts were only represented by few individuals. In September, two cohorts with modal lengths at $60-65 \mathrm{~mm}$ and $80-85 \mathrm{~mm}$ TL were found, whereas in October a small cohort of $<50 \mathrm{~mm}$ TL appeared, in addition to the majority of juveniles with modal lengths between $75-80 \mathrm{~mm}$ TL. The presence of multiple sprat cohorts in the GB was also apparent during two earlier field studies in 1987 (Alshut, 1988a) and 1991 (European Sardine-Anchovy-Recruitment-Project). Alshut (1988a) found two length maxima at 31-35 mm TL and 56-60 mm TL for juveniles sampled between September and November 1987, whereas in October 1991 she encountered two length groups with maxima at $50 \mathrm{~mm}$ and $75 \mathrm{~mm}$ TL. The latter is a similar situation to the one observed in October 2004. Both earlier studies also reported that sprat length distributions at different months were often not reconcilable with the progression of a distinct cohort from one survey to the next, but rather indicated a variable flux of individuals in and out of the study area (Alshut, 1988a; Knust unpublished data). In 2004, the distribution in October had no length peak that could possibly be attributed to the large modal length $(80-85 \mathrm{~mm} \mathrm{TL})$ of juveniles from the previous survey in September.

Our study is, however, only partially comparable to those earlier reports because of considerable differences in sampling gear and location. While we deployed relatively large pelagic trawl nets from mid-size research vessels (50-80 m length) within the entire GB, both earlier studies used a much smaller Rectangular-Midwater-Trawl (RMT, $5 \mathrm{~mm}$ stretched meshes) operated from small boats mainly in the shallow estuary of the river Eider $\left(54^{\circ} 07^{\prime} \mathrm{N} 8^{\circ} 22^{\prime} \mathrm{E}, 10 \mathrm{~m}\right.$ depth). Although Munk (1991b) found that an IKMT (Isaacs-Kid-Midwater Trawl, $5 \mathrm{~mm}$ stretched mesh in the cod end) yielded more reliable information on small fish abundance than a larger mesh, standard bottom trawl (Grand-Overt-Net with $20 \mathrm{~mm}$ stretched meshes in the cod end), the length distributions in our trawls did not indicate unrepresentative sampling of specimens $<5 \mathrm{~cm}$ TL. The fact that most juveniles in our study, particularly in August and September, were substantially bigger than those observed before, might rather have been a result of different spatial distributions of small and large sprat in the GB. Very small/young specimens may prefer the most shallow (Wadden Sea) parts of the GB, because these are characterized by higher temperatures (Temming and Damm, 2002), increased food concentrations (Tillmann et al., 2000) and potentially smaller/fewer predators. Size-dependent depth distributions are also known for juveniles of other fish taxa, such as flatfish settling in nearshore habitats (Gibson, 1973; Van der Veer et al., 2000). In our case, this could possibly explain why we sampled surprisingly few juveniles with hatch dates corresponding to the main spawning effort inside the GB (May-June).

A final supporting argument for the diverse structure of the juvenile sprat population in GB may be derived from our comparisons of back-calculated length and standardized increment width distributions. Our approach initially aimed at identifying patterns of potential selective mortality from one survey to the next, under the assumption that each survey targeted roughly the same population over time. We 
found that juveniles present in October were the smallest-at-age and on average slowest growing ones relative to the sampled population in September and August, which seemed inconsistent with the bigger-isbetter paradigm supported by a wealth of field and laboratory studies on larval fish (Anderson, 1988; Leggett and Deblois, 1994; Meekan and Fortier, 1996; Wilson and Meekan, 2002). For juveniles, Sogard (1997) similarly concluded that "when size-selective mortality has been detected in natural populations, it has generally been biased against small members of the population." However, after the effect of age on otolith growth rates was statistically removed, growth selection could not explain the found patterns. The distribution of growth phenotypes in October was not narrower than those in September or August, and even showed a decreased lower percentile indicative of the addition of previously absent slow growing individuals. If the same population is sampled repeatedly over time, any directional selection has to lead to reduced phenotype variability, and addition is impossible. Thus, we concluded that our initial assumption was not met, i.e., the surveys in August, September, and October at least partially sampled different juvenile sprat populations with different growth characteristics, possibly due to differences in spatio-temporal origin and environmental histories.

\subsection{Temperature-dependent growth}

The average sprat spawning effort coincides with the steady spring and summer warming in the North Sea, entailing that the later in the season sprat offspring are produced the warmer their experienced environment becomes. Given that within physiological limits and in the presence of sufficient food, development of larval fish in the sea accelerates with temperature (Pepin, 1991; Heath, 1992), such a temperature-mediated, seasonal growth increase should be detectable in the back-calculated pre-recruit otolith (as proxies for somatic) growth rates (e.g., Alshut, 1989). Our otolith microstructure analyses showed that, statistically, growth rates were primarily related to individual age. Rates continuously increased for about 40-60 days of age, after which they slowly decreased again until the day of capture. The seasonal, i.e. temperature effect consisted of broader maximum increments that were reached earlier after first increment formation, resulting in a steeper initial growth increase in later born individuals. A similar temperature effect has been demonstrated in sprat recruits from the Baltic Sea (Baumann et al., 2006c). The strong influence of temperature on sprat growth is also suggested by the fact that both in North and Baltic Sea sprat, a relatively coarse proxy for the experienced conditions, i.e. spatially integrated SST, explained a similarly high amount of variability in average back-calculated larval growth rates (33\%-53\%, Baumann et al., 2006c).

The annual cycle of warming and cooling in the North Sea entails fundamentally different growth conditions for early vs. late-in-theseason born sprat. Early born individuals face the disadvantage of a slower initial development, which prolongs the period of high vulnerability to the range of planktonic predators ("stage-duration" hypothesis, Leggett and Deblois, 1994). In case of survival to metamorphosis, however, they would have the advantage of experiencing favourably high temperatures throughout most of their post-larval and early juvenile stages, implying a potential for growth compensation, provided sufficient food resources. The more rapid development of latein-the-season born individuals may initially lead to lower cumulative mortalities, although higher ambient temperatures with entailing higher metabolic rates may also carry a higher starvation risk (Houde, 1989). During their postlarval development, late-born individuals will encounter substantially lower and decreasing ambient temperatures. Resultant growth reduction may outweigh the initial size benefit, and some individuals may fail to reach sizes necessary to join the schools of older conspecifics at the end of the growing season. Generally, however the risk of being born too early or too late in the season seems minimal for North Sea sprat, given the width of sprat survival windows relative to the spawning season. Both appear to be almost equally broad. This contrasts sharply with patterns found in Baltic Sea, where successful sprat survivors often originate from a much narrower time window (Baumann et al., 2008).

Our study emphasised the importance and the complex retention character of the nursery area German Bight, where multiple cohorts of sprat juveniles from a potentially wide range of North Sea areas, temporal origins, and therefore growth patterns may temporarily cooccur. Our understanding will improve further by approaches that try and resolve the spatio-temporal distribution of different juvenile sizeclasses in the GB by combining multiple sampling strategies for both open water and very shallow regions.

\section{Acknowledgments}

We thank all students and technicians who were involved in the sorting of ichthyoplankton samples at IfM-Geomar in Kiel. The "Bundesanstalt für Schifffahrt und Hydrography" (P. Löwe) is kindly acknowledged for providing the SST data for 2004. HamSOM circulation data were contributed by T. Pohlmann and W. Kühn. We further thank the officers and crews of the research vessels "Dana" (Denmark), "Heincke", "Alkor" and "Aade" (Germany) for their invaluable assistance in the field sampling. The study was funded by GLOBEC-Germany (BMBF, FKZ 03F0320E) and the Helgoland Foodweb Project (AlfredWegener-Institut). We are grateful to the entire GLOBEC-Germany community for making this ambitious field program work.

\section{References}

Alheit, J., Wahl, E., Cihangir, B., 1987. Distribution, abundance, development rates, production and mortality of sprat eggs. International Council for the Exploration of the Sea. ICES CM 1987/H:45.

Allain, G., Petitgas, P., Grellier, P., Lazure, P., 2003. The selection process from larval to juvenile stages of anchovy (Engraulis encrasicolus) in the Bay of Biscay investigated by Lagrangian simulations and comparative otolith growth. Fisheries Oceanography 12, 407-418.

Alshut, S., 1988a. Seasonal variations in length frequency and birthdate distribution of juvenile sprat (Sprattus sprattus). International Council for the Exploration of the Sea. ICES CM 1988/H:44:10

Alshut, S., 1988b. Daily growth increments on otoliths of laboratory-reared sprat Sprattus sprattus L., larvae. Meeresforschung 32, 23-29.

Alshut, S., 1989. Growth of larval and juvenile North Sea sprat, based on otolith growth increments. International Council for the Exploration of the Sea. ICES CM 1989/ $\mathrm{H}: 15: 12$.

Anderson, J.T., 1988. A review of size dependent survival during pre-recruit stages of fishes in relation to recruitment. Journal of Northwest Atlantic Fishery Science 8 , $55-66$.

Aurich, H.J., 1941. Die Verbreitung der pelagischen Fischbrut in der südlichen Nordsee während der Frühjahrsfahrten 1926-1937 der deutschen Forschungsschiffe Poseidon und Makrele. Helgoländer Wissenschaftliche Meeresuntersuchungen 2, 184-225.

Bartsch, J., Knust, R., 1994. Simulating the dispersion of vertically migrating sprat larvae (Sprattus sprattus (L.)) in the German Bight with a circulation and transport model. Fisheries Oceanography 3, 92-105.

Baumann, H., Pepin, P. Davidson, FJ.M., Mowbray, F, Schnack, D. Dower, JF, 2003. Reconstruction of environmental histories to investigate patterns of larval radiated shanny (Ulvaria subbifurcata) growth and selective survival in a large bay of Newfoundland. ICES Journal of Marine Science 60, 243-258.

Baumann, H., Hinrichsen, H.-H., Möllmann, C., Köster, F.W., Malzahn, A.M., Temming, A 2006a. Recruitment variability in Baltic sprat, Sprattus sprattus, is tightly coupled to temperature and transport patterns affecting the larval and early juvenile stages. Canadian Journal of Fisheries and Aquatic Sciences 63, 2191-2201.

Baumann, H., Hinrichsen, H.-H., Voss, R., Stepputtis, D., Grygiel, W., Clausen, L.W., Temming, A., 2006b. Linking growth-to environmental histories in central Baltic young-of-the-year sprat, Sprattus sprattus: an approach based on otolith microstructure analysis and hydrodynamic modeling. Fisheries Oceanography 15, 465-476.

Baumann, H., Gröhsler, T., Kornilovs, G., Makarchouk, A., Feldman, V., Temming, A., 2006c Temperature-induced regional and temporal growth differences in Baltic young-ofthe-year sprat, Sprattus sprattus. Marine Ecology Progress Series 317, 225-236.

Baumann, H., Voss, R., Hinrichsen, H.-H., Mohrholz, V., Schmidt, J.O., Temming, A., 2008. Investigating the selective survival of summer-over spring-born sprat, Sprattus sprattus, in the Baltic Sea. Fisheries Research 91,1-14.

Berghahn, R., 1996. Episodic mass invasions of juvenile gadoids into the Wadden Sea and their consequences for the population dynamics of brown shrimp (Crangon crangon). Pubblicazioni della Stazione Zoologica di Napoli I: Marine Ecology 17, 251-260.

Berghahn, R., Purps, M., 1998. Impact of discard mortality in Crangon fisheries on yearclass strength of North Sea flatfish species. Journal of Sea Research 40, 83-91. 
Bethke, E., Arrhenius, F., Cardinale, M., Håkansson, N., 1999. Comparison of the selectivity of three pelagic sampling trawls in a hydroacoustic survey. Fisheries Research 44, 15-23.

Bradford, M.J., 1992. Precision of recruitment predictions from early life stages of marine fishes. Fishery Bulletin US 90, 439-453.

Campana, S., 1990. How reliable are growth back-calculations based on otoliths? Canadian Journal of Fisheries and Aquatic Sciences 47, 2219-2227.

Gibson, R.N., 1973. The intertidal movements and distribution of young fish on a sandy beach with special reference to the plaice (Pleuronectes platessa L.). Journal of Experimental Marine Biology and Ecology 12, 79-102.

Halbeisen, H.-W., 1988. Bestimmungsschlüssel für Fischlarven der Nordsee und angrenzender Gebiete. Berichte aus dem Institut für Meereskunde 178, 76.

Heath, M.R., 1992. Field investigations of the early life stages of marine fish. Advances in Marine Biology 28, 1-174.

Houde, E.D., 1989. Comparative growth, mortality, and energetics of marine fish larvae: temperature and implied latitudinal effects. Fishery Bulletin US 87, 471-495.

ICES, 2007. Report of the herring assessment working group south of $62^{\circ} \mathrm{N}$ (HAWG). International Council for the Exploration of the Sea, ICES CM 2007/ACFM:11, 546pp.

Johnson, P.O., Dawson, W.A., 1975. The distribution of eggs and larvae of some pelagic fish species in the central and southern North Sea during June 1972. International Council for the Exploration of the Sea, p. 21. ICES CM 1975/H:13.

Krause, G., Budeus, G., Gerdes, D., Schaumann, K., Hesse, K., 1986. Frontal systems in the German Bight and their physical and biological effects, Marine interfaces ecohydrodynamics. In: Nihoul, J.C.J. (Ed.), Elsevier Oceanography Series, pp. 119-140. Amsterdam, Oxford, New York NY.

Leggett, W.C., Deblois, E., 1994. Recruitment in marine fishes: is it regulated by starvation and predation in the egg and larval stages? Netherlands Journal of Sea Research 32, 119-134

Malzahn, A., Boersma, M., 2007. Year-to-year variation in larval fish assemblages of the Southern North Sea. Helgoland Marine Research 61, 117-126.

Meekan, M.G., Fortier, L., 1996. Selection for fast growth during the larval life of Atlantic cod Gadus morhua on the Scotian shelf. Marine Ecology Progress Series 137, 25-37.

Munk, P., 1991a. Growth and drift pattern of larval sprat (Sprattus sprattus) in the eastern North Sea investigated by otolith microstructure analysis. International Council for the Exploration of the Sea. ICES CM 1991/L:36:11.

Munk, P., 1991b. Changes in mean size and distribution of juvenile North Sea sprat (Sprattus sprattus) in the period 1976-90. International Council for the Exploration of the Sea. ICES CM 1991/H:41:15.

Munk, P., 1993. Differential growth of larval sprat (Sprattus sprattus) across a tidal front in the eastern North Sea. Marine Ecology Progress Series 99, 17-29.

Otto, L., Zimmerman, J.T.F., Furnes, G.K., Mork, M., Saetre, R., Becker, G., 1990. Review of the physical oceanography of the North Sea. Netherlands Journal of Sea Research 26, 161-238.

Pepin, P., 1991. Effect of temperature and size on development, mortality, and survival rates of the pelagic early life history stages of marine fish. Canadian Journal of Fisheries and Aquatic Sciences 48, 503-518.

Pepin, P., Dower, J.F., Benoit, H.P., 2001. The role of measurement error on the interpretation of otolith increment width in the study of growth in larval fish. Canadian Journal of Fisheries and Aquatic Sciences 58, 2204-2212.
Petereit, C., Haslob, H., Kraus, G., Clemmesen, C., 2008. The influence of temperature on the development of Baltic Sea sprat (Sprattus sprattus) eggs and yolk sac larvae. Marine Biology 154, 295-306.

Pingree, R.D., Griffiths, D.K., 1978. Tidal fronts around the shelf seas around the British Isles. Journal of Geophysical Research 83, 4615-4622.

Pohlmann, T, 2006. A meso-scale model of the central and southern North Sea: consequences of an improved resolution. Continental Shelf Research 26, 2367-2385.

Ré, P., Gonçalves, E., 1993. Growth of sprat Sprattus sprattus larvae in the German Bight (North Sea) as inferred by otolith microstructure. Marine Ecology Progress Series 96 139-145.

Robert, D., Castonguay, M., Fortier, L., 2007. Early growth and recruitment in Atlantic mackerel Scomber scombrus: discriminating the effects of fast growth and selection for fast growth. Marine Ecology Progress Series 337, 209-219.

Shields, R.J., 1989. Studies of growth and nutritional status in 0-group sprat, Sprattus sprattus (Clupeidae), using otolith microstructure and lipid analytical techniques. $\mathrm{PhD}$ Thesis, University of Wales, Bangor, school of ocean sciences, Menai Bridge, Gwynedd, 163pp.

Shoij, J., Tanaka, M., 2006. Growth-selective survival in piscivorous larvae of Japanese Spanish mackerel Scomberomorus niphonius: early selection and significance of ichthyoplankton prey supply. Marine Ecology Progress Series 321, 245-254.

Sissenwine, M.P., 1984. Why do fish populations vary? In: May, R. (Ed.), Exploitation of Marine communities. Springer-Verlag, Berlin, pp. 59-94.

Sogard, S., 1997. Size-selective mortality in the juvenile stage of teleost fishes: a review. Bulletin of Marine Science 60, 1129-1157.

Otolith microstructure examination and analysis. In: Stevenson, D.K., Campana, S.E. (Eds.), Canadian Special Publication of Fisheries and Aquatic Sciences, vol. 117. 126 pp.

Temming, A., Damm, U., 2002. Life cycle of Crangon crangon in the North Sea: a simulation of the timing of recruitment as a function of the seasonal temperature signal. Fisheries Oceanography 11, 45-58.

Thompson, B.M., Milligan, S.P., Nichols, J.H., 1981. The development rates of sprat (Sprattus sprattus) eggs over a range of temperatures. International Council for the Exploration of the Sea. ICES CM 1981/H:15.

Tillmann, U., Hesse, K.-J., Colijn, F., 2000. Planktonic primary production in the German Wadden Sea. Journal of Plankton Research 22, 1253-1276.

Valenzuela, G., Vargas, C.A., 2002. Comparative larval growth rate of Sprattus sprattus in relation to physical and biological oceanographic features in the North Sea. Archive of Fishery and Marine Research 49, 213-230.

Valenzuela, G., Alheit, J., Coombs, S.H., Knust, R., 1991. Spawning patterns of sprat and survival chances of sprat larvae in relation to frontal systems in the German Bight. International Council for the Exploration of the Sea. ICES CM 1991/L:45.

Van der Veer, H.W., Berghahn, R., Miller, J.M., Rijnsdorp, A.D., 2000. Recruitment in flatfish, with special emphasis on North Atlantic species: progress made by the flatfish symposia. ICES Journal of Marine Science 57, 202-215.

Wahl, E., Alheit, J., 1988. Changes in distribution and abundance of sprat eggs during spawning season. International Council for the Exploration of the Sea. ICES CM 1988/H:45.

Wilson, D.T., Meekan, M.G., 2002. Growth-related advantages for survival to the point of replenishment in the coral reef fish Stegastes partitus (Pomacentridae). Marine Ecology Progress Series 231, 247-260. 